Orbis Tertius

ISSN: 1851-7811

publicaciones@fahce.unlp.edu.ar

Universidad Nacional de La Plata

Argentina

\title{
El poder del archivo y sus límites'
}

Mbembé2, Achille

El poder del archivo y sus límites ${ }^{1}$

Orbis Tertius, vol. 25, núm. 31, 2020

Universidad Nacional de La Plata, Argentina

DOI: https://doi.org/10.24215/18517811e154

Atribución no comercial compartir igual (CC BY-NC-SA) 4.0 


\section{El poder del archivo y sus límites ${ }^{1}$}

El término "archivos" primero se refiere a un edificio, un símbolo de una institución pública, uno de los órganos de un Estado constituido. Sin embargo, "archivos" también es entendido como una colección de documentos -normalmente escritos- guardados en este edificio. No puede por lo tanto haber una definición de "archivos" que no incluya tanto el edificio en sí como los documentos que almacena.

\section{DeL DOCUMENTO AL ARCHIVO}

El status y el poder del archivo derivan de esta imbricación entre edificio y documentos. El archivo no tiene ni status ni poder sin su dimensión arquitectónica, que incluye el espacio físico donde se sitúa el edificio, sus diseños y columnas, el ordenamiento de las habitaciones, la organización de los “documentos", el laberinto de corredores y ese grado de disciplina, media luz, y austeridad que le da al lugar algo de la naturaleza de un templo y de un cementerio: un espacio religioso, porque un conjunto de rituales es llevado a cabo allí constantemente; rituales que, como veremos luego, son de una naturaleza cuasi mágica; y un cementerio en el sentido de que fragmentos de vidas y piezas del tiempo están sepultados allí, sus sombras y huellas inscritas en un papel y preservadas como tantas reliquias. Y es así como llegamos a la materialidad ineludible del archivo y a su rol resultante, como este ensayo intentará demostrar, como una institución imaginaria.

En cuanto a los rituales involucrados, podríamos ver cómo un archivo es producido; esto es, el proceso que culmina en un texto "secular" con una función previa diferente y cuya carrera termina en los archivos -o mejor, que se convierte en archivo. Con frecuencia olvidamos que no todos los documentos están destinados a ser archivos. En cualquier sistema cultural, solo ciertos documentos cumplen el criterio de "archivabilidad". Excepto los documentos privados (de la Iglesia, de instituciones privadas, familiares, de empresas...), la mayoría de los documentos considerados como "archivables" están relacionados con el trabajo general del Estado. Una vez que son recibidos, deben ser codificados y clasificados. Luego, son distribuidos de acuerdo a criterios cronológicos, temáticos o geográficos. Sea cual fuere el criterio utilizado al momento de codificar, clasificar y distribuir, estos procedimientos son solamente una forma de crear un orden. Los documentos son entonces puestos en un sistema que facilita la identificación y la interpretación. Más seriamente, los documentos son puestos bajo un manto de secreto - por un período de tiempo que varía según la naturaleza de los documentos y la legislación local. El proceso que resulta en que un documento se convierta en "archivable" revela que solo hay productos que han sido deliberadamente despojados de lo que los haría simplemente documentos "seculares"; de este modo, no hay archivos de por sí.

Los archivos son el producto de un proceso que convierte un cierto número de documentos en ítems considerados dignos de conservación y mantenimiento en un espacio público, donde pueden ser consultados de acuerdo a procedimientos y regulaciones bien establecidas. Como resultado, se vuelven parte de un sistema 
especial, bien ilustrado por el recogimiento al secreto o al cierre que marca los primeros años de su vida. Durante varios años estos fragmentos de vida y piezas del tiempo están ocultos en la media luz, apartados del mundo visible. Una prohibición de principio les es impuesta. Esta prohibición convierte su contenido en algo aún más misterioso. Al mismo tiempo, un proceso de despojo y desposeimiento comienza: sobre todo, el documento archivado ha dejado en gran medida de ser propiedad de su autor para pasar a ser propiedad de la sociedad toda, aunque solo sea porque desde el momento en que es archivado, cualquiera puede reclamar el acceso a su contenido. Más allá del ritual de volver algo secreto, parece claro que el archivo es principalmente el producto de un juicio, el resultado del ejercicio de un poder y una autoridad específicos, que consiste en ubicar ciertos documentos en un archivo y, simultáneamente, descartar otros. El archivo, por lo tanto, es fundamentalmente un asunto de discriminación y selección, que al final, resulta en el otorgamiento de un status privilegiado a ciertos documentos escritos y el rechazo de ese mismo status a otros, así juzgados como "inarchivables". El archivo, así, no es un dato, sino un status.

\section{EL STATUS DEL RESTO}

¿De qué status estamos en verdad hablando? En primer lugar, es un status material. La naturaleza material del archivo - por lo menos antes de la digitalización- significa que está inscrito en el universo de los sentidos: un universo táctil porque el documento puede ser tocado; un universo visual porque puede ser visto; un universo cognitivo porque puede ser leído y decodificado. Consecuentemente, por el hecho de estar ahí, el archivo elimina la duda ejerciendo un poder debilitante sobre ella. Luego adquiere el status de prueba. Es la prueba de que una vida verdaderamente existió, de que algo realmente sucedió, de algo de lo que puede dar cuenta. El destino final del archivo está, por lo tanto, siempre fuera de su propia materialidad, en el relato que hace posible.

El suyo es también un status imaginario. Lo imaginario está caracterizado por dos propiedades mencionadas arriba: la naturaleza arquitectónica y la naturaleza religiosa del archivo. Ningún archivo puede ser el depositario de toda la historia de una sociedad, de todo lo que ha sucedido en esa sociedad. A través de documentos archivados, se nos presentan piezas de tiempo para ser ensambladas, fragmentos de vida a ser puestos en orden, uno tras otro, en un intento de formular un relato que adquiere su coherencia a través de la habilidad de armar vínculos entre el principio y el fin. Un montaje de fragmentos crea de este modo una ilusión de totalidad y continuidad. De este modo, igual que con el proceso arquitectónico, el tiempo entretejido por el archivo es el producto de una composición. Este tiempo tiene una dimensión política que resulta de la alquimia del archivo: se supone que debe pertenecer a todos. La comunidad del tiempo, el sentimiento según el cual todos seríamos herederos de un tiempo sobre el que ejerceríamos los derechos de la posesión colectiva: este es el imaginario que el archivo busca diseminar.

Este tiempo de co-posesión, sin embargo, descansa en un acontecimiento fundamental: la muerte. La muerte hasta el extremo de que el documento archivado, por excelencia, es, generalmente, un documento cuyo autor ha muerto y que, obviamente, ha estado cerrado por el período de tiempo requerido antes de poder ser accesible. El examen representado por esta clausura, la extensión del tiempo y la resultante distancia del presente, suma al contenido del documento que es propio del archivo. Sin contemplar casos excepcionales, es solo al final de este período de cierre que el documento archivado es despertado de un sueño y vuelto a la vida. Puede, de ahí en más, ser "consultado". El término "consultado" muestra claramente que ya no hablamos de cualquier documento, sino de este documento particular que tiene el poder, por una designación legal, de iluminar a aquellos comprometidos con una indagación sobre el tiempo heredado en co-posesión.

En un nivel más básico, el archivo impone una diferencia cualitativa entre la co-posesión de tiempo muerto (el pasado) y el tiempo vivo, esto es, el presente inmediato. Esa parte de su status, bajo el poder del imaginario, surge del hecho de que está enraizado en la muerte como un acontecimiento arquitectónico. Debe ocurrir una muerte para dar nacimiento a un tiempo caracterizado por no pertenecer a ningún individuo, 
precisamente porque este tiempo, a partir de ese momento, funda o instituye algo. El poder del archivo como una "institución imaginaria" se origina en gran medida en este intercambio con la muerte. Este intercambio tiene tres dimensiones. La primera involucra la lucha contra la dispersión de los fragmentos de vida. De hecho, la muerte es uno de los intentos más radicales de destruir la vida y exterminar cualquier deuda en su relación. El acto de morir, puesto que conlleva la dislocación del cuerpo físico, nunca ataca totalmente ni con el mismo éxito, todas las propiedades del fallecido (en sentido literal o figurativo). Siempre quedarán huellas del fallecido, elementos que testifican que esa vida sí existió, que hubo hechos vividos y luchas afrontadas o evadidas. Los archivos nacen del deseo de volver a montar estas huellas más que de destruirlas. La función del archivo es frustrar la dispersión de estas huellas y la posibilidad, siempre presente, de que de ser descuidadas, podrían eventualmente adquirir una vida propia. Fundamentalmente, los muertos deberían tener formalmente prohibido suscitar disturbios en el presente.

La mejor forma de evitar que los muertos no provoquen disturbios no es solo enterrarlos, sino enterrar sus restos, sus desechos. Los archivos forman parte de estos restos y desechos y es por eso que cumplen un rol religioso en las sociedades modernas. Pero -siempre recordando la relación entre el documento y el diseño arquitectónico que lo contiene- también constituye un tipo de sepulcro donde estos restos son puestos a descansar. En este acto de entierro y en relación a la sepultura, es que se encuentra la segunda dimensión del intercambio entre muerte y archivo. Archivar es un tipo de sepelio, poner algo en un ataúd, sino para que descanse, para enterrar elementos de esa vida que no pudo pura y simplemente ser destruida. Estos elementos, borrados del tiempo y la vida, son asignados a un lugar y a un sepulcro perfectamente reconocible porque está consagrado: los archivos. El asignarlos a este lugar hace posible establecer una autoridad incuestionable sobre ellos y domesticar la violencia y la crueldad de las que son capaces los restos, especialmente cuando estos son abandonados a sus propios dispositivos.

\section{EL ARCHIVO COMO TALISMÁN}

Hasta ahora hemos tratado los archivos desde la base de su poder como reliquias y su capacidad de funcionar como una institución imaginaria. Deliberadamente, hemos dejado de lado dos aspectos: la experiencia subjetiva e individual del archivo, y la relación entre el archivo y el Estado. En cuanto al primero, es suficiente decir que como sea que definamos los archivos, no tienen sentido fuera de la experiencia subjetiva de aquellos individuos que, en un momento dado, llegan a usarlos. Es esta experiencia subjetiva la que pone límites en el supuesto poder de los archivos, revelando su inutilidad y naturaleza residual y superflua. Varios factores están involucrados en esta experiencia subjetiva de los archivos: de quién son; de qué autoridad dependen; el contexto político en el que son visitados; las condiciones bajo las que se accede a ellos; la distancia entre lo que se busca y lo que se encuentra; la forma en la que son decodificados y cómo se presenta y se hace público aquello que fue encontrado allí.

La relación entre el archivo y el Estado es igual de compleja. Descansa en una paradoja. Por un lado, no hay Estado sin archivo -sin su archivo. Por el otro, la misma existencia del archivo constituye una constante amenaza al Estado. La razón es simple. Más que en su habilidad para recordar, el poder del Estado descansa en su habilidad para consumir tiempo, esto es, abolir el archivo y anestesiar el pasado. El acto que crea el Estado es un acto de "cronofagia". Es un acto radical porque consumir el pasado hace posible que esté libre de toda deuda. La violencia constitutiva del Estado descansa, al final, en la posibilidad, que nunca puede ser descartada, de rechazar el reconocimiento de una u otra deuda (o de saldarla). Esta violencia es definida en contraste con la misma esencia del archivo, ya que la negación del archivo es equivalente, stricto sensu, a la negación de la deuda.

Este es el motivo por el cual, en ciertos casos, algunos Estados pensaron que podían existir sin archivos. Por eso han intentado ya sea reducirlos al silencio o, en un modo más radical, destruirlos. Haciendo esto creyeron que podían diferir la habilidad del archivo de servir de prueba de un fragmento sospechoso de vida o de una 
pieza de tiempo. Más interesados en el presente que en el futuro, pensaron que podían eliminar el pasado de una vez por todas, así podían escribir como si todo comenzara de nuevo. Es porque, en última instancia, estos métodos afectan la materialidad del archivo más que su dimensión como institución imaginaria, que, en ocasiones, tuvieron problemas.

El poder del archivo, por todo esto, no ha sido abolido. Por el contrario, ha sido, más bien, desplazado. La destrucción material solo ha tenido éxito en la inscripción de la memoria del archivo y sus contenidos en un doble registro. Por un lado, en la fantasía, puesto que la destrucción o la prohibición del archivo solo lo dotó de más contenido. En este caso, ese contenido es más irreal, porque ha sido ocultado y enterrado una vez y para siempre en la esfera de lo que se mantendrá desconocido, haciendo así espacio para todas las formas de pensamiento imaginario. Por otro lado, el archivo destruido acosa al Estado en la forma de un fantasma, un objeto que no tiene sustancia objetiva, pero que, por estar tocado por la muerte, es transformado en un demonio, el receptáculo de todos los ideales utópicos y de toda la ira, la autoridad de un juicio futuro.

Por el contrario, otros Estados han buscado "civilizar" las formas en que el archivo es consumido, no intentando destruir su sustancia material, sino a través de una inclinación por la conmemoración. En este marco, el objetivo final de la conmemoración es menos recordar, que olvidar. Para que exista un recuerdo, debe primero existir la tentación de repetir un acto original. La conmemoración, en contraste, es parte del ritual del olvido: ofrece una despedida al deseo o la voluntad de repetir algo. "Aprender" a olvidar es mucho más fácil si, por un lado, lo que debe ser olvidado pasa al folklore (cuando es entregado al público en general) y si, por el otro, pasa a ser parte del universo de lo que se vuelve mercancía. Así, pasamos del consumo por parte de un Leviathan que busca liberarse de toda deuda (esto es, adquirir el derecho a ejercer violencia absoluta), al consumo delas masas - consumo masivo.

Democratizando el acto de la cronofagia y volviendo a un orden en que el consumo del archivo se transforma en una herramienta comunal del Estado y de la sociedad, surgen dos posibilidades que la represión sola no permite. Por un lado, se atenúa la necesidad que habría significado un deseo por repetir, en un tiempo diferente y con otros actores, el acto original. En los casos en los que el acto involucraba un asesinato, un asesino o una masacre, no es difícil ver lo beneficios que una sociedad ganaría de tal recorte. Por otro lado, haciendo que tal recorte forme parte del universo de la mercancía, gracias al consumo masivo, el archivo es retirado de la esfera de los restos y desechos y transformado en un talismán. Resulta un culto pagano en cuyo corazón se pueden encontrar muchos otros artefactos e instituciones (museos, por ejemplo).

La transformación del archivo en un talismán, sin embargo, está acompañada por la remoción de cualquier factor subversivo de la memoria. Al darle a quien lo lleva (en este caso a quien lo consume) la sensación de estar protegido o de ser el co-dueño de un tiempo o el co-actor en un evento, aun en el pasado, el talismán suaviza la ira, la vergüenza, la culpa, o el resentimiento que el archivo si no incita, mantiene, por su función de recordar. Así, el deseo de venganza es eliminado junto con el deber del arrepentimiento, la justicia y la reparación. La transformación en mercancía de la memoria oblitera la distinción entre la víctima y el verdugo y, en consecuencia, habilita al Estado a concretar lo que siempre ha soñado: la disolución de la deuda y la posibilidad de empezar de cero.

\section{ConCLUSIón}

Examinar archivos es estar interesado en lo que la vida ha dejado atrás, es estar interesado en la deuda. Sin embargo, también es estar preocupado por el resto. En este sentido, tanto el historiador como el archivista habitan un sepulcro. Mantienen una relación íntima con un mundo vivo solo por virtud de un evento inicial que es representado por el acto de morir. Siendo este el caso, escribir la historia solo supone manipular archivos. Seguir huellas, volver a armar fragmentos y reconstruir restos es estar implicado en un ritual que culmina en la resucitación de la vida, en el devolverles la vida a los muertos reintegrándolos en el ciclo del 
tiempo, de un modo que encuentren en un texto, en un artefacto o en un monumento, un lugar que habitar, desde el que continúen expresándose.

Lidiar con la muerte también evoca la posibilitad del fantasma. El archivo no podría tener una relación con la muerte sin incluir el otro remanente de la muerte, el fantasma. En gran medida, el historiador libra una batalla contra este mundo de fantasmas. Estos encuentran en los textos escritos el camino a una existencia entre los mortales - pero una existencia que ya no se desarrolla de acuerdo a la misma modalidad que lo hacía en su tiempo. Puede ser que la historiografía y la misma posibilidad de una comunidad política (polis), sean solo concebibles bajo la condición de que el fantasma, que ha sido vuelto a la vida de esta manera, deba quedar en silencio, deba aceptar que de ahora en más deba hablar a través de otro, o ser representado por algún signo, o algún objeto que, sin pertenecer a nadie en particular, les pertenece a todos.

Siendo este el caso, el historiador no está satisfecho con traer a la muerte de vuelta a la vida. Él o ella la devuelven a la vida precisamente para silenciarla mejor, transformándola de palabras autónomas en una muleta en la que apoyarse para hablar y escribir más allá de un texto original. Es a través de la inclinación de este acto de desposesión -el dejar fuera al autor- que el historiador establece su autoridad y que la sociedad establece su dominio específico: el dominio de las cosas que, porque compartidas, pertenecen exclusivamente a nadie (el dominio público).

Y este es el motivo por el que el historiador y el archivista han sido muy útiles al Estado, notablemente en contextos en los que el segundo era designado guardián del dominio de las cosas que no le pertenecen a nadie. De hecho, tanto el historiador como el archivista ocupan una posición estratégica en la producción de una institución imaginaria. Uno podría preguntar cuál será su rol de ahora en adelante, especialmente en contextos donde el proceso de democratización de un acto cronofágico -esto es, la disolución del archivose encuentra en un estado avanzado.

Lo curioso es la creencia largamente sostenida de que el Estado descanse en algo más que el deseo de destruir el archivo, de liberarse de los restos. ¿Qué podría ser más noble? Pero quizás es una condición para la existencia de todas las sociedades: la necesidad permanente de destruir los restos, de apaciguar, violentamente si es necesario, el demonio que llevan consigo.

\section{Notas}

1 En Hamilton C., V. Harris, J. Taylor, M. Pickover, G. Reid y R. Saleh (Ed.). Refiguring the Archive. Ciudad del Cabo, Sudáfrica: David Philip Publishers, 2002, 19-26. Este texto fue traducido del francés al inglés por Judith Inggs para el libro en que salió publicado. Es un ensayo, como los demás, fruto de un proyecto llevado a cabo en la Universidad Witwatersrand de Johannesburgo. Parte del proyecto fue la realización de trece seminarios de los que participaron veintidós oradores, la mayoría de ellos sudafricanos y algunos extranjeros, como el mismo Achille Mbembé o Jacques Derrida. El libro compila ensayos que, en el marco del seminario, se desarrollaron como aproximaciones teóricas más o menos exploratorias, y otros que fueron directamente redactados para esta publicación. Todos se centran en el discurso sobre el archivo, sus limitaciones teóricas, su potencia y los problemas y cuestiones más o menos específicas del contexto sudafricano.

2 Achille Mbembé (1957, Camerún) es Profesor en el Wits Institute for Social and Economic Research de la Universidad Witwatersrand de Johannesburgo. Obtuvo su título de Doctor en Historia en La Sorbona, París. Enseñó en varias universidades de los Estados Unidos como Columbia, Yale, Berkeley y Harvard. Fue Director del Consejo para el Desarrollo de la Investigación en Ciencias Sociales en África, con sede en Dakar. Su producción intelectual estuvo siempre enfocada en los estudios poscoloniales, la historia africana, la filosofía y la política. Uno de sus aportes más importantes es el concepto de "necropolítica" como contraparte del foucaultiano "biopolítica", en tanto revela los mecanismos del poder que regulan no solo la muerte, sino la exposición a ella. Sus libros más reconocidos son: $D e$ la postcolonie. Essai sur l'imagination politique dans lAfrique contemporaine (Karthala, 2000) traducido como On the Postcolony (University of California Press, 2001), Critique de la raison nègre (Éditions La Découverte, 2013) traducido como Critique of Black Reason (Duke University Press, 2016), Necropolitics (Duke University Press, 2019) y Out of the Dark Night. Essays on Decolonization (Columbia University Press, 2020). En español, pueden leerse Necropolitica (Melusina, 2010) y Critica de la razón negra (Futuro Anterior, 2016). 
Carla Fumagalli, et al. El poder del archivo y Sus límites ${ }^{1}$

CC BY-NC-SA

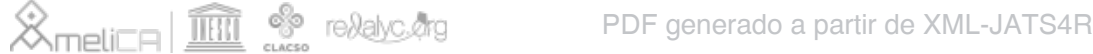

